\title{
ALTERNÂNCIA VOCÁLICA DAS FORMAS VERBAIS E NOMINAIS DO PORTUGUÊS BRASILEIRO PARA APLICAÇÃO EM CONVERSÃO TEXTO-FALA
}

\author{
Izabel C. Seara, Sandra G. Kafka, Simone Klein e Rui Seara
}

\begin{abstract}
Resumo-Este artigo investiga novas estratégias para tratamento da alternância vocálica no português falado no Brasil para aplicação em sistemas de conversão texto-fala. Temos buscado resolver esse problema, baseando-nos em uma adequada identificação das classes gramaticais, tais como verbos e nomes. São discutidas as diferentes fases necessárias à concepção de um parser morfossintático, bem como as principais técnicas para geração da alternância vocálica em situações gerais e em outras bastante restritas. Os resultados dos testes mostraram que as regras de alternância dos sons vocálicos, propostas neste artigo, resolvem a maior parte dos problemas concernentes às diferenças entre nomes e verbos.
\end{abstract}

Palavras-Chave: alternância vocálica, conversão texto-fala, parser morfossintático.

\begin{abstract}
Ahstract - This paper investigates new strategies to deal with the alternation in vowel quality of the Portuguese spoken in Brazil for application in text-to-speech systems. Based on an adequate identification of the grammatical classes, such as verbs and nouns, we have sought to solve such a problem. A general insight of the different phases needed to conceive a morphosyntactic parser as well as the main techniques for generating vowel alternation, in both general and restricted cases, are discussed. Test results showed that the vowel sound alternation rules proposed in this paper solve most problems concerning the differences between verbs and nouns.
\end{abstract}

Keywords: alternation in vowel quality, text-to-speech, morphosyntactic parser.

\section{INTRODUÇÃO}

Atualmente existem diversos sistemas de conversão texto-fala para o português falado no Brasil (doravante $P B$ ) [1-6]. As técnicas utilizadas nos diferentes estágios desses sistemas são muitas vezes distintas, mas seu objetivo final é a pronúncia correta da representação do texto de entrada com a máxima inteligibilidade e naturalidade na fala sintetizada. No entanto, um problema ainda não totalmente resolvido para o PB [1-4], no que concerne à pronúncia correta, é a alternância vocálica das formas verbais e nominais.

Esta alternância se deve à existência de duas transcrições para as vogais $e$ e $o$ não acentuadas graficamente no interior

Izabel C. Seara, Sandra G. Kafka, Simone Klein e Rui Seara estão atuando no LINSE - Laboratório de Circuitos e Processamento de Sinais, Departamento de Engenharia Elétrica, Universidade Federal de Santa Catarina. E-mails: \{izabels, kafka, klein, seara\} @linse.ufsc.br.

Editores responsáveis: Antonio Sérgio Bezerra Sombra, Ricardo Menezes Campello de Souza e Max Gerken. Data de recebimento: 31/Dez/2001; data da revisão: 15/Mar/2002; data de aceitaçāo: 08/Abr/2002. de palavras, podendo ser abertas (é, ó) ou fechadas (ê, ô). As regras ortográfico-fonéticas, elaboradas para o conversor texto-fala por nós desenvolvido, resolveram a maior parte dos problemas de abertura e fechamento vocálicos. Porém, restaram ainda as formas homógrafas não homófonas (mesma grafia com pronúncia diferenciada) cuja distinção entre verbos e nomes se apóia na abertura e fechamento da vogal. Por exemplo, em: Eu olho para o problema com olho clínico (formas homógrafas não homófonas), a primeira vogal o da forma verbal olho é aberta [o], enquanto, na forma nominal, essa mesma vogal é fechada [o].

Além das homófonas, ainda temos problemas de abertura vocálica na $1^{\underline{\underline{n}}}, 2^{\underline{\underline{a}}}$ e $3^{\underline{a}}$ pessoas do singular e $3^{\underline{\underline{n}}}$ do plural em algumas conjugações verbais, para as quais as regras ortográfico-fonéticas não são satisfatórias, gerando vogais abertas quando deveriam ser fechadas e vice-versa. A frase: Meta-se com uma grande equipe e acerte a meta, ilustra esses problemas.

Assim, neste artigo, propõe-se a elaboração de uma etapa dentro do processamento lingüístico, visando resolver os supramencionados problemas de alternância vocálica. Como a classificação morfossintática foi elaborada através de diferentes etapas, cada uma tentando classificar itens lexicais que apresentavam comportamentos semelhantes (classes fechadas e classes abertas, por exemplo), a etapa de alternância vocálica ocupa a última posição nos níveis de classificação morfossintática, já que depende essencialmente de uma correta classificação de verbos e nomes.

A Seção 2 apresenta a descrição do sistema vocálico segundo seus traços fonológicos, juntamente com as regras fonológicas necessárias à altemância vocálica. A Seção 3 mostra as diferentes etapas do processamento lingüístico em um sistema de conversão texto-fala. $\mathrm{Na}$ Seção 4, apresentam-se os diferentes estágios de um parser morfossintático elaborado para a realização de uma classificação gramatical consistente, principalmente de verbos e nomes. A Seção 5 descreve as regras para a geração da alternância vocálica usando a classificação dos radicais verbais, rotulados segundo seus diferentes esquemas casuais. Na Seção 6, apresentam-se alguns dos resultados obtidos com a implementação das regras propostas nas Seções 4 e 5 . Finalmente, na Seção 7 , são apresentadas as conclusões deste trabalho.

\section{FORMALIZAÇÃO LINGÜÍSTICA DO SISTEMA VOCÁLICO DO PORTUGUÊS FALADO NO BRASIL}

Os sistemas lingüísticos são formalizados através da organização dos sons da língua segundo sua estrutura e funcionamento, sendo essa sistematização objeto de estudo da fonologia. Esses sistemas lingüísticos também podem ser 
formalizados pelo estudo dos sons da fala do ponto de vista articulatório (articulação e produção dos sons da fala pelo aparelho fonador), acústico (propriedades físicas da produção e propagação dos sons) e perceptual (percepção dos sons), objeto de estudo da fonética.

Com o objetivo de tentar estabelecer relações entre o nível fonético e o fonológico, descrevendo e analisando como as línguas organizam os sons da fala, surgem as diferentes teorias fonologicas [7]. Conforme essas teorias, os sistemas vocálicos podem ser descritos segundo uma combinação de traços distintivos. Assim, as vogais em posição tônica no $\mathrm{PB}$ podem ser descritas pelos seguintes traços [8]:

\begin{tabular}{|c|c|c|}
\hline Yogais & Não-Arredondada & Arredondada \\
\hline Alta & /i/ & $/ \mathrm{u} /$ \\
\hline Média Alta & /e/ & /0/ \\
\hline Média Baixa & $/ \varepsilon /$ & $/ 0 /$ \\
\hline Baixa & & $\mid \mathrm{a} /$ \\
\hline & Anterior & Posterior \\
\hline
\end{tabular}

Figura 1. Quadro dos traços fonológicos das vogais orais do PB.

A partir destes traços, podenıs dizer, por exemplo, que a vogal $i(/ i /)$ pode ser descrita como uma vogal alta, anterior, não arredondada, diferenciando-se da vogal $u$ $(/ \mathrm{u} /)$ que é posterior e arredondada. Assim, quando falamos em vogais altas, estamos nos referindo às vogais $i \mathrm{e}$ $u$, já que possuem o traço [+alto]. Quanto à vogal $a(/ \mathrm{a} /)$, diferencia-se dessas duas anteriores por ser uma vogal baixa central.

Com estes traços, podemos perceber, de forma mais clara, as regras fonológicas das formas verbais do PB que levam ou não à altemância vocálica.

No português falado no Brasil, a altemância vocálica afeta as formas verbais, cujos radicais possuem vogal média alta $/ e, o /$ ou média baixa $/ \varepsilon, o /{ }^{1}$. Segundo seus traços fonológicos, as vogais médias altas /e, o/ são caracterizadas pelos traços [-alto] e [-baixo] e as médias baixas $/ \varepsilon, o /$ pelos traços [-alto] e [+baixo] (ver Fig. 1).

Pode-se ver então que as vogais $/ \varepsilon$, o/ são mais baixas (razão do traço [+baixo]) do que as vogais /e, o/ (razão do traço [-baixo]), diferenciando-se as vogais médias altas das médias baixas pelo traço [ \pm baixo]. Já, as vogais médias /e, $\varepsilon, o$, o/ são menos altas (razão do traço [-alto]) do que as vogais altas / $i, u$ / (razão do traço [+alto]), sendo o traço [ \pm alto] o elemento diferenciador entre vogais médias e altas.

De acordo com $[7,9]$, um caso restrito de altemância vocálica é a harmonia verbal que se processa em verbos de vogal temática ${ }^{2}-e$ e $-i \quad\left(2^{\underline{a}}\right.$ e $3^{\underline{a}}$ conjugações, respectivamente) e estabelece que a última vogal do radical (exceto /a/) se harmoniza em altura com a vogal tenútica do verbo em questão. Dessa forma, seriam harmônicas a

\footnotetext{
${ }^{1}$ Os símbolos $/ e, \quad o /$ correspondem a $(\hat{e}, \quad \hat{o})$ e, $/ \varepsilon, \quad o /$ correspondem a $(\dot{e}, 6)$.

${ }^{2}$ Vogal que determina a que conjugação pertence o verbo.

$1^{\mathrm{a}}$ pessoa do singular do Presente do Indicativo e todas as pessoas do Presente do Subjuntivo.

$$
[\text { sent-i }]+0] \rightarrow[\sin t+0] \rightarrow[\text { sinto }]
$$

Em (1), há uma harmonização dos traços da vogal do radical do verbo orientada pela vogal temática, pois a vogal temática de sentir $[i]^{3}$ tem o traço fonológico [+alto] e a vogal do radical [e] em [sent-] tem o traço [-alto]. Assim, a vogal do radical passa de [-alta] a [+alta $]^{4}$.

O problema para a conversão texto-fala ocorre, no entanto, em formas verbais para as quais a regra de harmonia vocálica não se aplica, isto é, em todas as pessoas do Presente do Indicativo e do Subjuntivo dos verbos de $1^{\underline{a}}$ conjugação e na $2^{\underline{a}}$ e $3^{\underline{a}}$ pessoas do singular e $3^{\underline{a}}$ do plural desses mesmos tempos verbais para os verbos da $2^{\underline{a}}$ e $3^{\underline{a}}$ conjugações. Para essas formas, é aplicada a regra de abaixamento vocálico, que só se processa em vogais com o traço [+acento] se a regra de harmonização vocálica não for aplicada. Por exemplo, em:

$$
\text { (Tu) }[\mathrm{beb}+\mathrm{e}]+\mathrm{s}] \text {, }
$$

a vogal do radical tem a mesma altura da vogal temática, ou seja, é [-alta], não se aplicando a regra de harmonização vocálica. Por conseguinte, as regras de acento e de abaixamento se aphicam.

A regra de acento preceitua que a vogal de um radical verbal recebe o traço [+acento] quando está diante de consoante seguida de vogal e de outra consoante (sílaba tipo CVC) ou consoante seguida de vogal em final de palavra (CV\#). Pela regra de acento, em:

$$
\text { (Tu) }[\text { beb+e]+s] }]_{\text {verbo }} \text {, }
$$

temos [' beb+e]+s] $]^{5}$, isto é, a primeira vogal do radical verbal transforma-se na tônica, ou seja, apresenta o traço [+acento], já que é seguida por uma sílaba tipo CVC.

A regra de abaixamento estabelece que uma vogal com os traços [-aito] e [+acento] se toma [+baixa]. Essa regra, aplicada depois da regra de acento, leva ['beb+e]+s] a ['beb+e]+s], ou seja, a vogal acentuada média alta [e] passa a vogal média baixa $[\varepsilon]^{6}$.

A resolução deste problema depende de uma classificação morfossintática bem elaborada. Assim, neste artigo, apresentaremos regras de alternância vocálica que estão inseridas no módulo de classificação gramatical (parser morfossintático). A correta representação da altemância vocálica dependerá de mecanismos de classificação gramatical suficientemente robustos para uma boa identificação de duas classes gramaticais, verbo e nome, necessária às regras de altemância vocálica.

\footnotetext{
${ }^{3}$ Vogal temática [i] corresponde à $3^{\mathfrak{9}}$ conjugação.

${ }^{4}$ Para uma melhor observação da mudança de traços fonológicos da vogal do radical, veja a descrição das vogais do português falado no Brasil, apresentada na Fig. 1.

${ }^{5} \mathrm{O}$ diacrítico ' é uma notação fonológica e indica que a silaba posterior ao diacrítico é a tônica.

${ }^{6}$ Esta problematização foi um pouco sintetizada sendo colocada em uma linguagem mais acessível a não lingüistas, como é o caso da maior parte dos interessados em sistemas de conversāo texto-fala.
} 


\section{PROCESSAMENTO LINGÜíSTICO EM UM SISTEMA DE CONVERSÃO TEXTO-FALA}

Em sistemas de conversão texto-fala [1-6,10-13], as etapas concernentes ao processamento lingüístico são bastante importantes na etapa de síntese da fala. Para se ter uma idéia das etapas constituintes de um sistema de conversão texto-fala, elaboramos o diagrama da Fig. 2.

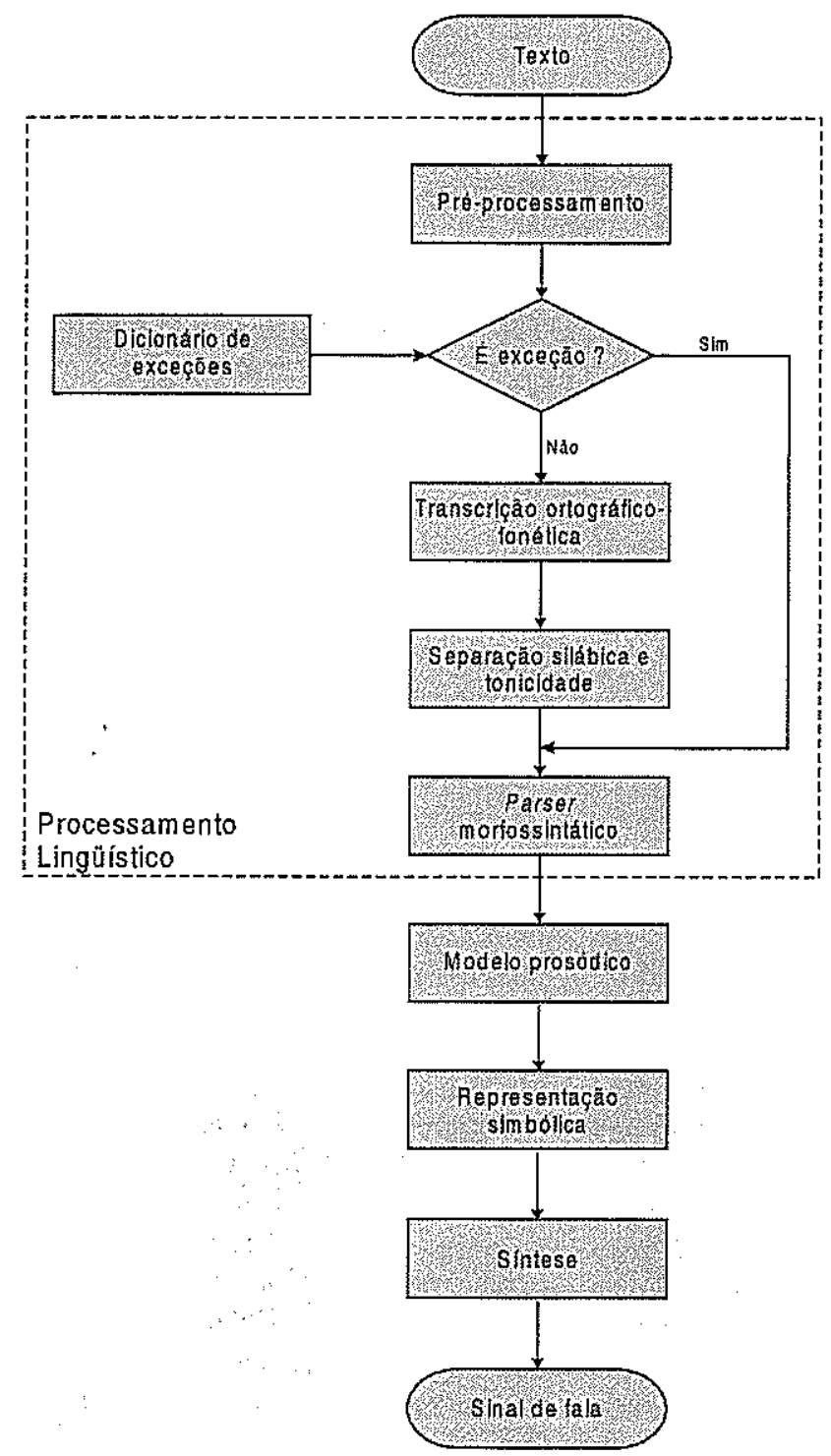

Figura 2. Diagrama das etapas do processo de conversão texto-fala.

Neste diagrama, percebe-se que a parte lingiística tem uin peso bastante grande em todo o sistema, orientando inclusive a etapa de modelagem prosódica. Esta dependerá basicamente das informações linguísticas das etapas anteriores para modificação de seus parâmetros prosódicos, ou seja, duração, intensidade e freqüência fundamental.

Pela Fig. 2, vê-se o Processamento Linguiístico iniciado com a etapa de Pré-processamento que, dentre outras tarefas, expande números e abreviaturas mais comuns.

A segunda etapa constitui-se do dicionário de exceções que comporta palavras que apresentam algum problema de transcrição; palavras estrangeiras incorporadas à língua portuguesa; radicais e desinências verbais.

A transcrição ortográfico-fonética compreende a terceira fase deste processamento. Nela, são codificados os sons referentes às palavras convertidas, apresentando as regras gerais de conversão grafema (unidade de um sistema de escrita que, na escrita alfabética, corresponde às letras) para fonema (unidade sonora da fala) [14]. A etapa seguinte concerne à separação silábica e identificação da silaba tônica de cada palavra.

O processamento lingüístico é finalizado pela etapa de classificação morfossintática. Nessa etapa, as palavras são automaticamente etiquetadas por suas respectivas classes morfológicas e, quando necessário, recebem o ajuste de abertura ou fechamento vocálico restritivo aos itens lexicais que podem ser tanto formas verbais quanto nominais.

Assim, observa-se que os estágios necessários à geração de regras para a alternância vocálica estão inseridos na etapa do parser morfossintático.

\section{CLASSIFICAÇÃO GRAMATICAL}

O parser motfossintático elaborado para um conversor texto-fala opera em cinco estágios:

i) inserção de palavras pertencentes a classes gramaticais fechadas em una biblioteca com um trabalho manual de etiquetagem de classes gramaticais, radicais e desinências verbais;

ii) geração de regras para desambigüização dos itens lexicais que possuem nuais de uma classe gramatical;

iii) comparação dos itens lexicais ainda não classificados com os radicais e desinências inseridas nas bibliotecas do prinueiro estágio;

iv) geração de regras para classificação gramatical dos itens lexicais pertencentes a uma biblioteca, chamada TIPONOMEVER, que comporta os itens classificados no terceiro estágio como verbo [VER], mas que podem ser tanto nome [NOME] quanto verbo [VER];

v) geração de regras de alternância vocálica.

No primeiro estágio, são colocados em uma bibhoteca os itens lexicais pertencentes às classes gramaticais fechadas, isto é, aquelas que apresentam um número bastante limitado de elementos, tais como artigos, pronomes, preposições, conjunções e os advérbios mais frequientes, com suas respectivas classificações.

Neste estágio, alguns dos itens lexicais são etiquetados com várias classes. Isso ocorre, por exemplo, $\operatorname{com} a$, já que ele pode ser artigo (ART):

a menina;

pronome denionstrativo (DEM):

Essa boneca é bonita, mas a que eu te dei é mais;

pronome oblíquo átono (OBA):

Aquela boneca, comprei-a para minha filha;

e preposição (PREP)

Ele o pagou em prestações a perder de vista.

Neste mesmo estágio, em uma outra biblioteca, são etiquetados as desinências e os radicais verbais, juntamente com o código correspondente ao tipo de alternância requerido (abertura para o verbo e fechamento para o nome 
ou vice-versa), levando em conta também a que conjugação pertence o radical, conforme (5).

\section{Govern- (Código 5) [Primeira conjugação]}

[fecha no nome, abre no verbo]

No segundo estágio, é feita a "desambigüização" dos itens lexicais que receberam, no primeiro estágio, mais de uma classe gramatical, como $o a$ anteriormente classificado, que foi etiquetado com quatro classes gramaticais (ART, DEM, OBA e PREP).

Neste segundo estágio, formulam-se, então, regras que possibilitam uma única classificação. Para o caso dos exemplos (4.b) e (4.c) apresentados anteriormente, têm-se:

$$
\begin{aligned}
& \text { Exemplo }(4 . b)^{7} \\
& \operatorname{SE}(([i] \in \mathrm{C} 1) \mathbf{E}([i+1] \in \mathrm{D} 2)) \Rightarrow[i]=\mathrm{DEM} \\
& \text { Exemplo }(4 . c)^{8} \\
& \text { SE }(([i] \in \mathrm{Cl}) \mathbf{E}([i-1]=\mathrm{VER}) \mathbf{E}([i+1]=\text { PREP })) \Rightarrow \\
& {[i]=\mathrm{OBA}}
\end{aligned}
$$

No terceiro estágio, os itens lexicais ainda não classificados são comparados aos radicais e desinências inseridos nas bibliotecas do primeiro estágio. Se esses itens correspondem perfeitamente à estrutura [RAD+DESGERAL] $]^{\text {, }}$ são classificados como verbo [VER], se correspondem à estrutura $[R A D+D E S N O M I N A L]^{10}$, são classificados como forma verbo-nominal [VERN] $]^{11}$. Ao contrário, se não comportarem estas estruturas, são classificados como nome [NOME].

No quarto estágio, são geradas regras para a classificação dos itens lexicais que, no terceiro estágio, foram etiquetados como verbo [VER] e que pertencem à biblioteca TIPONOMEVER. Assim, baseando-se na classificação imserida nos dois primeiros estágios, é elaborado um diagrama de estados que inicia sua classificação a partir das classificações anteriores. Desta forma, tem-se:

\section{$O$ acordo foi fechado.}

Eu acordo cedo.

Eu, acordo, não faço não.

\section{Eu alinoço em casa.}

O diagrama de estados apresentado na Fig. 3 cobre todos os estados necessários à classificação das palavras dos exemplos (6a), (6b), (6c) e (6d).

\footnotetext{
${ }^{7} \mathrm{Cl}=$ grupo constituído pelos artigos definidos; [i] $=$ item lexical-alvo; $[i+1]=i t e m$ lexical posterior; $D 2=$ =grupo constituído pelo pronome relativo que; DEM=grupo constituído pelos itens lexicais classificados como pronome demonstrativo.

${ }^{8}$ [i-1]=item lexical anterior; VER=grupo constituído pelos itens lexicais classificados como verbo; $P R E P=g r u p o$ constituído pelos itens lexicais classifificados como preposiçãa; $\mathrm{OBA}=$ grupo constituído pelos itens lexicais classificados como pronome oblíquo átono.

${ }^{9} \mathrm{RAD}=$ radical verbal; DESGERAL=desinências verbais, exceto as desinências nominais.

${ }^{10}$ DESNOMINAL=desinências nominais dos verbos no particípio regular, gerúndio e infinitivo impessoal.

11 VERN=forma nominal do verbo.
}

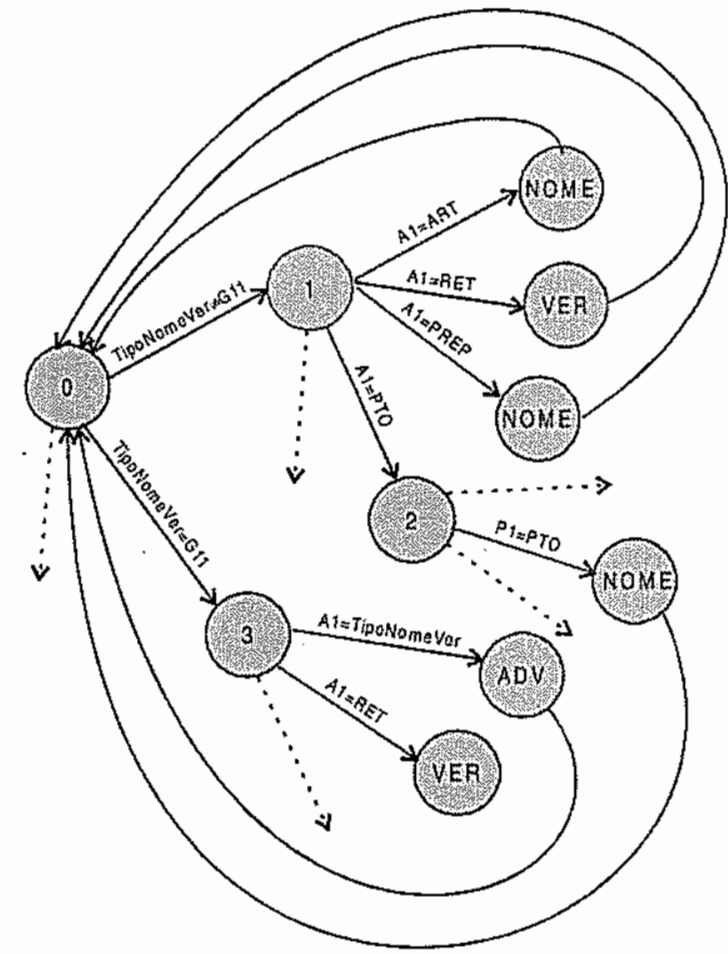

Figura 3. Diagrama de estados para classificação morfossintática dos itens lexicais do exemplo $(6)^{12}$.

No exemplo (6a), ocorre a pré-classificação de $o$ como artigo [ART]; foi como verbo [VER]; fechado como forma verbo-nominal [VERN], faltando apenas a classificação da palavra acordo. Como acordo não pertence ao grupo G11, o diagrama aponta para o estado 1 . Nesse estado, observa-se que o item anterior à palavta acordo foi pré-classificado como artigo [ART], assim acordo é classificado como [NOME] e o diagrama volta ao estado 0 .

No exemplo (6b), ocorre a pré-classificação de $e u$ como pronome do caso reto [RET], faltando ainda a classificação das palavras acordo e cedo. Como acordo não pertence ao grupo G11, o diagrama remete ao estado 1 . Nesse ponto, tem-se o item anterior à palavra acordo classificado como pronome pessoal do caso reto [RET], fazendo com que acordo seja classificado como verbo [VER], retomando ao estado 0. Prosseguindo a classificação, temos cedo pertencente ao grupo G11, fazendo com que o diagrama parta do estado 0 para o estado $3 \mathrm{e}$, sendo o item lexical anterior a cedo pertencente à biblioteca TIPONOMEVER, o diagrama classifica o item cedo como advérbio [ADV], retornando ao estado 0 .

No exemplo $(6 \mathrm{c})$, acontece a pré-classificação de eu como pronome pessoal do caso reto [RET], de não como advérbio $[\mathrm{ADV}]$, de faço como verbo [VER] ${ }^{13}$, faltando

\footnotetext{
${ }^{12}$ TIPONOMEVER=biblioteca constituída por itens lexicais que podem ser tanto verbo [VER] quanto outra classe qualquer, como, por exemplo, casa e cedo; G11=itens lexicais que podem ser tanto

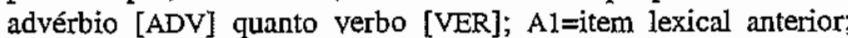
$\mathrm{P} 1=$ item lexical posterior; $\mathrm{PTO}=$ marcas de pontuação (ponto final, vírgula, ponto e vírgula, dois pontos, exclamaçāo ou interrogação, travessäo).

${ }^{13}$ Como este item lexical apresenta radical e desinência, será classificado exclusivamente como verbo, pois, diferentemente de casa que tanto pode ser verbo quanto nome, ele não farł parte do dicionário TIPONOMEVER.
} 
apenas a classificação de acordo. Como acordo não pertence a G11 e seus itens lexicais anterior e posterior são marcas de pontuação (vírgulas), o diagrama remete ao estado 2 e classifica acordo como [NOME], retomando ao estado 0 .

No exemplo (6d), temos a pré-classificação de $e u$ como pronome pessoal do caso reto [RET], de em como preposição [PREP], faltando-nos ainda classificar os itens almoço e casa. Como almoço não pertence ao grupo G11 e é antecedido por um item lexical classificado como [RET], o diagrama remete ao estado 1 e classifica almoço como verbo [VER], retornando, em seguida, ao estado 0. Como casa também não pertence ao grupo G11 e o item anterior foi pré-classificado como preposição [PREP], o diagrama remete ao estado 1 e classifica casa como [NOME], retornando ao estado 0 .

O quinto estágio é o foco deste trabalho e depende basicamente de uma classificação consistente de verbos e nounes no quarto estágio. Para o quinto estágio, foi elaborada uma divisão dos radicais necessários à identificação das formas verbais em 9 casos.

\section{GERAÇÃO DE REGRAS PARA A ALTERNÂNCIA VOCÁLICA}

Somente passarão pelo quarto estágio, o de geração de regras para a alternância vocálica, e receberão a nova classificação os radicais cujas vogais são afetadas pela alternância vocálica. Esses radicais foram etiquetados manualmente em 9 casos, uma vez que a alternância vocálica se dá, como veremos abaixo, de maneira diferenciada.

As regras de transcrição ortográfico-fonética resolveram grande parte dos problemas de abertura e fechamento vocálico. Porém, trouxeram alguns problemas para os itens lexicais ambíguos quanto à sua classificação gramatical, mais precisamente para aqueles que podiam ser verbos ou nomes, (Eu almoço e $O$ almoço) e também para algumas desinências e radicais verbais. Por exemplo, na forma verbal termos ( $1^{\underline{a}}$ pessoa do plural do Infinitivo Pessoal), a fala sintetizada especificava a primeira vogal da desinência verbal como [+baixa] [ $\varepsilon$ ], ao invés de especificá-la como [-baixa] [e]. Assim, esses casos também seriam candidatos potenciais para o estágio de alternância vocálica.

Esquemas de classificação prévia dos radicais:

CASO 1 - radicais de verbos da $1^{\underline{a}}$ conjugação que podem ser classificados ora coino nome ora como verbo e cuja vogal do radical deve ser aberta, traço [+baixo], para a $1^{\underline{\underline{a}}}, 2^{\underline{a}}$ e $3^{\underline{a}}$ pessoas do singular e $3^{\underline{a}}$ do plural do Presente do Indicativo (7a), do Presente do Subjuntivo (7b) e do Imperativo. Sendo, nos nomes (NOME) $(7 \mathrm{c}$ ), mantida a transcrição apresentada pelas regras ortográfico-fonéticas.

$$
\begin{gathered}
\text { Ex.: Eu almoço. (ó) } \\
\qquad \begin{array}{c}
\text { Que ele almoce. (ó) } \\
\text { O almoço. }(\hat{o})
\end{array}
\end{gathered}
$$

do Presente do Subjuntivo (8a) e do Imperativo (8b) e é aberta, traço [+baixo], para a $2^{\underline{a}}$ e $3^{\underline{a}}$ pessoas do singular e $3^{\underline{a}}$ do plural dos verbos do Presente do Indicativo (8c).

Ex.: Que eu beba. $(\hat{e})$

No verão, beba muito líqüido. (̂)

Ele bebe. (é)

CASO 3 - radicais de verbos da $3^{2}$ conjugação cuja vogal do radical é aberta, ou seja, tem o traço [+baixo], somente para a $2^{\underline{a}}$ e $3^{\underline{a}}$ pessoas do singular (9a) e $3^{\underline{a}}$ do plural (9b) dos verbos do Presente do Indicativo.

Ex.: Tu dormes. (ó)

Eles dormem. (ó)

CASO 4 - formas verbais cuja alteração vocálica ocorre na desinência verbal ${ }^{14}$, ou seja, a primeira vogal da desinência é aberta, traço [+baixo], e as regras de transcrição ortográfico-fonética não resolveram essa alteração.

Ex.: Se eu tiver um livro. (é)

Eles tiveram de sair cedo. (é)

CASO 5 - radicais de verbos da $1^{\underline{a}}$ conjugação que podem ser classificados ora como nome ora como verbo e cuja vogal do radical é fechada, ou seja, tem o traço [-baixo] para os nomes (11a) e é aberta, traço [+baixo], para a $1^{a}, 2^{a}$ e $3^{\underline{a}}$ pessoas do singular e $3^{\underline{a}}$ do plural do Presente do Indicativo (11b) e do Presente do Subjuntivo (11c).

Ex.: O governo. $(\hat{e})$

Eu governo. (é)

Que ele governe. (é)

CASO 6 - radicais verbais cuja vogal deve ser sempre fechada, ou seja, ter o traço [-baixo].

Ex.: Tu chegas sempre na mesma hora. $(\hat{e})$

CASO 7 - a alteração vocálica ocorre na desinência verbal, sendo a vogal da desinência fechada, ou seja, tem o traço [-baixo], para o verbo (13a) e é aberta, traço [+baixo], para os nomes (13b).

\section{Ex.: Eu'vou colher uma flor. $(\hat{e})$

$$
\text { A colher de pau. (é) }
$$

CASO 8 - formas verbais cuja alteração vocálica ocorre na desinência verbal, ou seja, a primeira vogal da desinência é fechada, traço [-baixo] e as regras de transcrição ortográfico-fonética não resolveram essa alteração. Isso ocorre nas $2^{\underline{a}}$ e $3^{\underline{a}}$ pessoas do singular e $1^{\underline{a}}$ e $3^{\underline{a}}$ do plural dos verbos no Pretérito Perfeito e Mais-que-Perfeito do Indicativo; no Pretérito Imperfeito (14) e Futuro do Subjuntivo e no Infinitivo Pessoal.

Ex.: Se eles abatessem o pássaro, eu choraria. ( $\hat{e})$

\footnotetext{
${ }^{14}$ Para facilitar a concepção dos dicionários de radicais e desinências, incluímos a vogal temática na desinência verbal.
}

CASO 2 - radicais de verbos da $2^{\underline{a}}$ conjugação cuja vogal do radical é fechada, ou seja, tem o traço [-baixo] na $I^{\underline{a}}$ pessoa do Presente do Indicativo e em todas as pessoas 
CASO 9 - radicais de verbos da $2^{\underline{a}}$ conjugação cuja vogal do radical é fechada, ou seja, tem o traço [-baixo] na $1^{\underline{3}}$ pessoa do Presente do Indicativo e em todas as pessoas do Presente do Subjuntivo e do Imperativo (15a) e é aberta, traço [+baixo], para a $2^{\underline{a}}$ e $3^{\underline{a}}$ pessoas do singular e $3^{\underline{2}}$ do plural dos verbos do Presente do Indicativo (15b) e para os nomes (15c).

Ex.: Meta-se com seus pares. ( $\hat{e})$

Ele mete os pés na porta. (é)

A meta é escrever. (é)

A partir da classificação de formas nominais e verbais nos 9 casos anteriormente elencados, criou-se um bloco para as regras de alteração vocálica de radicais e desimências. Esse bloco levará em consideração, para a elaboração de suas regras, o código de alternância (CASOS) e a desinência verbal. Nos casos $1,2,3,4,6$ e 8, as regras só foram válidas para as palavras classificadas como verbos (VER), nos demais casos, foram feitas regras dependentes da classificação verbo (VER) ou nome (NOME).

A seguir, apresentaremos algumas das regras elaboradas para a alteração vocálica ${ }^{15}$ :

Para o CASO 1:

1) $\mathrm{SE}(([\mathrm{i}]=\mathrm{VER}) \quad \mathrm{E}(\mathrm{CASO}=1) \quad \mathrm{E}([\mathrm{DESA}]=0)) \Rightarrow$ $[\operatorname{RAD}-1]=[+$ baixo $](\operatorname{ver}(7 \mathrm{a}))$.

Para o CASO 2:

1) SE $(([i]=V E R) \quad \mathrm{E}(\mathrm{CASO}=2) \quad \mathrm{E}([\mathrm{DESA}]=a)) \Rightarrow$ $[R A D-1]=[$-baixo] $(\operatorname{ver}(8 \mathrm{a}))$.

2) SE (([i] $=$ VER $) \quad \mathrm{E}(\mathrm{CASO}=2) \quad \mathrm{E}([\mathrm{DESA}]=e)) \Rightarrow$ $[\mathrm{RAD}-1]=[+$ baixo $](\operatorname{ver}(8 \mathrm{c}))$.

Para o CASO 3:

1) $\mathbf{S E}(([\mathrm{i}]=\mathrm{VER}) \mathbf{E}(\mathrm{CASO}=3) \mathbf{E}([\mathrm{DESA}]=e s)) \Rightarrow$ $[$ RAD-1] $=[+$ baixo] $(\operatorname{ver}(9 a))$.

Para o CASO 4:

1) $\mathrm{SE}(([\mathrm{i}]=\mathrm{VER}) \quad \mathrm{E}(\mathrm{CASO}=4) \quad \mathrm{E}([\mathrm{DESA}]=e r)) \Rightarrow$ $[$ DES-1] $=[+$ baixo $]($ ver $(10 a))$.

Para o CASO 5:

1) $\mathrm{SE}(([\mathrm{i}]=\mathrm{NOME} \mathbf{E}(\mathrm{CASO}=5) \quad \mathbf{E}([\mathrm{DESA}]=0)) \Rightarrow$ $[\mathrm{DES}-1]=[$-baixo] $($ ver $(11 \mathrm{a}))$.

2) $\mathrm{SE}(([\mathrm{i}]=\mathrm{VER}) \mathrm{E}(\mathrm{CASO}=5) \quad \mathrm{E}([\mathrm{DESA}]=0)) \Rightarrow$ $[\mathrm{DES}-1]=[+$ baixo $]($ ver $(1 \mathrm{lb}))$.

Para o CASO 6:

1) $\mathrm{SE}(([\mathrm{i}]=\mathrm{VER}) \quad \mathrm{E}(\mathrm{CASO}=6) \quad \mathbf{E}([\mathrm{DESA}]=a s)) \Rightarrow$ $[$ RAD-1] $=[$-baixo] $($ ver $(12))$.

\footnotetext{
${ }^{15} \mathrm{DESA}=$ Formas desinenciais utilizadas na altemância vocálica; NOME=Grupo constituído pelos itens lexicais classificados como nomes; [RAD-1] =Ultima vogal do radical; [DES-1]=Primeira vogal da desinência; [+baixo]=Vogal será aberta, ou seja, terá o traço [+baixo]; [-baixo]=Vogal será fechada, ou seja, terá o traço [-baixo].
}

Para o CASO 7:

1) $\mathrm{SE}(([\mathrm{i}]=\mathrm{VER}) \mathbf{E}(\mathrm{CASO}=7) \quad \mathbf{E}([\mathrm{DESA}]=e r)) \Rightarrow$ [DES-1] $=[$-baixo] $(\operatorname{ver}(13 a))$.

2) $\mathrm{SE}(([\mathrm{i}]=\mathrm{NOME} \mathbf{E}(\mathrm{CASO}=7) \mathbf{E}([\mathrm{DESA}]=e r)) \Rightarrow$ [DES-1] $=[+$ baixo $]($ ver $(13 b))$.

Para o CASO 8:

1) $\mathrm{SE}(([\mathrm{i}]=\mathrm{VER}) \mathbf{E}(\mathrm{CASO}=8) \mathbf{E}([\mathrm{DESA}]=$ essem $) \Rightarrow$ $[\mathrm{RAD}-1]=[$-baixo] $(\operatorname{ver}(14))$.

Para o CASO 9:

1) $\mathrm{SE}(([\mathrm{i}]=\mathrm{VER} \quad \mathrm{E} \quad(\mathrm{CASO}=9) \quad \mathbf{E}([\mathrm{DESA}]=a)) \Rightarrow$ [RAD-I] $=[$-baixo] $($ ver $(15 \mathrm{a})$ )

2) $\mathrm{SE}(([\mathrm{i}]=\mathrm{VER} \quad \mathbf{E}(\mathrm{CASO}=9) \quad \mathbf{E}([\mathrm{DESA}]=e)) \Rightarrow$ $[\mathrm{RAD}-1]=[+$ baixo $](\operatorname{ver}(15 \mathrm{~b}))$

3) $\mathrm{SE}(([\mathrm{i}]=\mathrm{NOME}) \mathbf{E}(\mathrm{CASO}=9) \mathbf{E}([\mathrm{DESA}]=a)) \Rightarrow$ $[\mathrm{RAD}-1]=[+$ baixo $](\operatorname{ver}(15 \mathrm{c}))$.

\section{RESULTADOS}

A partir da implementação das regras apresentadas na Seção 5, foram feitos testes exaustivos, buscando observar o maior número possível de palavras que pudessem apresentar problemas de alternância vocálica. Através de um software de procura automática, obtivemos um corpus de frases contendo diversos exemplos de itens lexicais concernentes às regras de alternância apresentadas nos CASOS 1 a 9.

O software de busca automática trazia exemplos passíveis de aplicação das regras de altemância vocálica, conforme palavras em negrito nos exemplos abaixo:

Cerca de io pessoas estavam na agência, que não possui porta giratória e nem detector de metais.

De acordo com o registro no Centro de Operaçōes da Polícia Militar (Copom), foram roubados cerca de $R \$ 15$ mil e duas armas dos vigias.

Nestes testes, obteve-se êxito na pronúncia da fala sintetizada para praticamente todos os itens testados. A maior parte dos erros de classificação eram referentes à desambigüização de classes. A taxa de acerto nesse caso ficou em torno de $98,9 \%$.

As regras aqui exibidas, além de resolverem problemas do tipo: Quero que ele corte a carne com o corte que a corte recomendar, no qual o verbo (ele corte) e o substantivo masculino (o corte) possuem a vogal de seus radicais aberta (traço [+baixo]) e o substantivo feminino (a corte) possui essa mesma vogal fechada (traço [-baixo]), levaram à diminuição do número de itens inseridos no dicionário de exceções.

\section{CONCLUSÕES}

Com as regras propostas neste artigo, resolvemos grande parte dos problemas relacionados à abertura e fechamento vocálicos das formas nominais e verbais. Algumas dessas regras funcionam para casos bastante restritos, mas foram necessárias para uma correta pronúncia da representação do texto de entrada. 
Até o momento, a maior parte dos sistemas de conversāo texto-fala para o PB não havia dado tratamento especial a esta questão, fazendo simplesmente observaçōes quanto aos problemas que poderiam surgir referentes às vogais e e $\mathrm{o}$, ou sugerindo que os itens lexicais que apresentassem dificuldades fossem inseridos em dicionários de exceções, gerando um aumento desnecessário em tais dicionários.

Os problemas que ainda não foram resolvidos dizem respeito às regras de classificação gramatical, ou seja, alguns itens lexicais são classificados como verbos [VER] quando deveriam ter sido classificados como nomes [NOME] e vice-versa. Sendo assim, ocorre uma inversão de altemância nas vogais dos radicais, abrindo quando deveriam fechar e fechando quando deveriam abrir. No entanto, se a classificação gramatical for correta, as regras de alternância vocálica apresentadas funcionam satisfatoriamente. Em algumas situaçōes, deve-se optar por uma classificação ou outra, levando em consideração a aplicação para a qual está voltado o sistema de conversão texto-fala. Por exemplo, para aplicação em sistemas de consulta à lista telefônica, consideramos que, quando o item lexical passível de alternância vocálica estiver sozinho ou seguido de outro item classificado como NOME, sua classificação será NOME.

Exemplo:

\section{Posto Estrela}

Gelo Cristal

Os pequenos problemas ainda não solucionados envolvem o nível semântico, mas não são desencorajadores, já que o processo de ajuste fino em sistemas de conversão texto-fala é bastante delicado e evolutivo.

\section{AGRADECIMENTOS}

Agradecemos à Empresa de Telecomunicações DÍGITRO Tecnologia Ltda. pelo financiamento dado a esta pesquisa.

\section{REFERÊNCIAS}

[1] F. Egashira, "Sńntese de voz a partir de texto para a língua portuguesa," Dissertaçăo de Mestrado, Unicamp, Campinas, Jul. 1992 ,

[2] C. H. Silva, "Modelamento prosódico para conversão texto-fala do português falado no Brasil," Dissertação de Mestrado, Unicamp, Campinas, Dez. 1995.

[3] L. C. T. Gomes, "Sistema de conversão texto-fala para a língua portuguesa utilizando a abordagem de síntese por regras," Dissertação de Mestrado, Unicamp, Campinas, Jul. 1998.

[4] P. A. Aquino, "O papel das vogais reduzidas pós-tônicas na construção de um sistema de síntese concatenativa para o português do Brasil," Dissertação de Mestrado, Unicamp, Campinas, Nov, 1997.

[5] M. N. Souza, L. P. Calôba, J. M. Seixas, C. G. Machado e M. V. Ludolf, "Sintetizador de voz do projeto Processador Automático de Português," Proceedings of XII Brazilian Automatic Control Conference - XII CBA, Uberlândia, MG, vol. VI, pp. 2093-2096, Set. 1998.

[6] F. A. Figueiredo, L. A. B. Naviner e B. G. Aguiar Neto, "Uma nova abordagem para o sistema de conversão texto-fala para a língua portuguesa," $X V$ Simpósio Brasileiro de Telecomunicações, Recife, PE, pp.328-331, Jan. 1997.
[7] L. Bisol, Introdução a estudos de fonologia do português brasileiro. Porto Alegre: EDIPUCRS, 1996.

[8] J. M Câmara Jr., Estrutura da lingua portuguesa. Petrópolis: Vozes, 1970.

[9] M. H. M. Mateus, Aspectos de fonologia do português. Lisboa: Centro de Estudos Filológicos, 1975.

[10] D. H. Klatt, "Review of text-to-speech conversion for English," Joumal of the Acoustical Society of America, vol. 82, no. 3, pp. 737-793, Sept. 1987.

[11] M. Edgington, A. Lowry, P. Jackson, A. P. Breen e S. Minnis, "Overview of current text-to-speech techniques: Part I - text and linguistic analysis," BT Technol $J$, vol. 14, no. I, pp. 68-83, Jan. 1996.

[12] T. Dutoit, An introduction to text-to-speech synthesis. Dordrecht: Kluwer, 1997.

[13] R. V. Cox, C. A. Kamm, L. R. Rabiner, J. Schroeter e J. G. Wilpon, "Speech and language processing for next-millenium communication services," Proceedings of the IEEE, vol. 88, no. 8, pp. 1314-1337, Aug. 2000.

[14] A. Houaiss e M. S. Villar. Dicionário Houaiss da língua portuguesa. Rio de Janeiro: Objetiva, 2001.

Izabel Christine Seara obteve, pela Universidade Federal de Santa Catarina, os títulos de Licenciada em Letras: Português-Francês, Mestre e Doutora em Lingüística em 1990, 1994 e 2000, respectivamente. É professora de Lingüística e Produção Textual e pesquisadora na área de Processamento da Fala, desenvolvendo pesquisas no Laboratório de Circuitos e Processamento de Sinais (LINSE) do Departamento de Engenharia Elétrica da Universidade Federal de Santa Catarina. Suas áreas de interesse são: Fonética Acústica e Articulatória, Síntese e Reconhecimento de Fala.

Sandra Ghizoni Kafka graduou-se em Letras: Português-Italiano em 1994 pela Universidade Federal de Santa Catarina e tornou-se Mestre em Lingüística pela mesma Universidade em Junho de 1999. Atualmente é pesquisadora na área de Processamento da Fala, atuando no Laboratório de Circuitos e Processamento de Sinais (LINSE) do Departamento de Engenharia Elétrica da Universidade Federal de Santa Catarina. Suas áreas de interesse são: Fonética Acústica, Síntese e Reconhecimento de Fala e Identificação de Locutores.

Simone Klein graduou-se em Letras: Alemão-Bacharelado em Tradução e obteve o título de Mestre em Lingüística pela Universidade Federal de Santa Catarina em 1994 e 1999, respectivamente. Desenvolve atualmente pesquisas na área de Processamento da Fala, atuando no Laboratório de Circuitos e Processamento de Sinais (LINSE) do Departamento de Engenharia Elétrica da Universidade Federal de Santa Catarina. Tem interesse pelas seguintes áreas de estudo: Fonética Acústica, Síntese e Reconhecimento de Fala.

Rui Seara graduou-se em Engenharia Elétrica pela Universidade Federal de Santa Catarina (UFSC), Florianópolis, SC, em 1975. Obteve o título de Mestre em Ciências em Engenharia Elétrica pela UFSC, em 1980. Especializou-se em InstrumentaçãoMetrologia pela Ecole Supérieure d'Electricité de Paris, França, em 1982. Obteve o título de Doutor em Engenharia Elétrica pela Université Paris Sud de Paris, França, em 1984. Ingressou no Departamento de Engenharia Elétrica da UFSC em 1976, onde atualmente é Professor Titular e desenvolve suas atividades de pesquisa e ensino nas áreas de: Filtros Analógicos e Digitais, Filtragem Adaptativa, Processamento de Imagens e Processamento da Fala. 